\title{
Muscle Characteristics and Meat Quality of Lambs, Grown on Different Nutritional Planes. III. Effect on Muscle Ultrastructure
}

\author{
A. Asghar* and Marine F. Yeates \\ Department of Animal Science, New England University, Armidale, N.S.W., Australia \\ Received June 5, 1978
}

The effect of maintenance (zero-energy balance) and submaintenance (negative-energy balance) and of subsequent compensatory growth (repletion) on the micro- and ultrastructure of $L$. dorsi muscle from young lambs was investigated. This study showed that fibre diameter and sarcomere length did not change significantly due to maintenance feeding but submaintenance feeding caused a marked decreased in these parameters. The microscopic appearance of collagen was a dense, course fibrillar type, and occurred in thicker bundles in the muscle of under-fed lambs. However, the nature elastin was similar in all lambs.

The under-feeding also caused pronounced reduction in the amount of glycogen granules and the number of mitochomdria in muscle. The sarcoplasmic reticulum and T-system did not seem to be related to the nutritional status of the animals. The myofibrils remained normal during maintenance feeding, whereas submaintenance feeding resulted in some degeneration of actin and myosin filaments. However, there was no difference in the sarcomere periodicity or banding pattern of the normal portions of degenerated myofibrils.

The general features and appearance of fibres, and the fine structure of myofibrils and cellular components of the muscle from the replenished lambs became identical to that of normally grown lambs at the same age. The collagen, however, was still moderately dense and the fat cells were small in the repleted lambs.

Mason" stated that chronic underfeeding causes a general decrease in the size of muscle cells or fibres, as happens in disease atrophy. Quin ${ }^{2)}$ expressed the belief that severe inadequate feeding produces irreversible injury to fibres and result in dystrophy of fat and muscle. However, Yeates' work $^{3}{ }^{\prime}$ indicated that the decrease in cross sectional area of muscle following nutritional stress, even down to the lowest limits compatible with maintaining life, does not necessarily cause permanent damage to the muscle. The study on subcellular aspects has shown gross reduction in the endoplasmic reticulum in the liver cells of rats, kept on inadequate diet, ${ }^{4,5}$ whereas only minimum changes in other organs such as the pancreas, heart and jejunum were observed. ${ }^{5}$ ) This suggests a state of cellular adaptation rather than irreversible injury in the latter organs.

* Present address: Department of Food Technology, University of Agriculture, Fasialabad, Pakistan.
However little information is available on structural changes in skeletal muscle from undernourished ruminants. This paper presents the influence of maintenance (zeroenergy balance), submaintenance (negativeenergy balance) feeding and of subsequent compensatory growth (repletion) on the microstructural features of lambs muscle.

\section{EXPERIMENTAL}

The experimental designs for maintenance (zeroenergy balance) submaintenance (negative-energy balanace) feeding and of compensatory growth (repletion), genetic background of the lambs, and the detail of the treatments have been explained in Part $\mathrm{I}^{\mathrm{B})}$ Samples from left $L$. dorsi muscle (between 13th thoracic to 2 nd lumbar region) were removed by a sharp cylindrical punch usually within two minutes after bleeding the animals. They were immediately fixed for light and election microscopy as follows:

1. Light microscopy. About half inch $(1.25 \mathrm{~cm})$ diameter core samples were first fixed in Susa solution ${ }^{\text {?) }}$ then treated according to the standard procedure to prepare transverse and logitudinal sections $(8 \sim 12 \mu$ 
thick) and stained in Orcein and Van Gieson by a method modified from Carleton and Drury ${ }^{7}$ for differential staining of the muscle components. Observations were made on quantity, type and distribution of muscle fibres, collagen, elastin and fat; muscle fibre diameter and sarcomers lengths were also measured.

2. Electron microscopy. Samples were cut into about $0.5 \mathrm{~mm}$ pieces and fixed for an hour in $1 \%$ osmium tetroxide, buffered with veronal acetate at $\mathrm{pH}$ 7.4. ${ }^{8}$ The tonicity was controlled by the addition of sucrose, the osmotic strength being 480 milliosmols. ${ }^{\text {) }}$ Dehydration and infiltration were carried out according to Lufts' method ${ }^{10)}$ for Epon 812. Sections were cut at $400 \sim 600 \AA$ in a longitudinal plane of orientation of the muscle fibres by LKB ultratome with a glass knife. They were stained with saturated aqueous solution of uranyl acetate and double stained with Reynolds' lead citrate. ${ }^{11)}$ The electron micrographs were taken by a Siemens Elmiakop or Phillips EM 200.

\section{RESULTS}

The experimental data are presented in Table I and Figs. 1 to 5. The discussion on the effects of the different nutrition regimes on various microstructural features of lambs' muscle ( $L$. dorsi) follows below.

\section{A. Effect of zero- and negative-energy balance} feeding on structural aspects of muscle

1. Muscle fibre diameter. Table I records the information on the diameter of muscle fibre of lambs which were kept on maintenance feeding and that of controls. Although there was considerable variation within each group, the animals kept on maintenance feeding had a smaller mean fibre diameter than that of the control animals, the difference, however, was not significant $(36.1 \mu$ vs. $39.3 \mu ; 0.05<P<$ 0.1 ). This suggests that loss in body weight is evidently necessary to cause a pronounced decrease in the diameter of the muscle fibres.

The effect of submaintenance feeding on the fibre diameter can also be seen in Table I. The underfed group II had a very reduced mean fibre diameter as compared to group III $(P<0.01)$ and group I $(P<0.001)$. The latter two groups were not significantly different from each other. The decrease in fibre diameter and an increase in the water content of muscle (reported in Part II) ${ }^{12)}$ due to undernutrition suggests that the water increased mainly in the extra-cellular spaces; otherwise there should have been little or no change in fibre diameter. These results agree with earlier reports that severe undernutrition causes an increase in extra-cellular fluid $^{13,14)}$ and a decrease in the muscle fibre diameter. ${ }^{3,15}$ Contrary to this, Hight and Barton ${ }^{16)}$ did not find any adverse effect of undernutrition on fibre diameter, in spite of severe weight loss in sheep.

2. Sarcomere length. Sarcomere length differed between groups (Table I), the mean values for maintenance and control groups respectively being $1.39 \mu$ and $1.52 \mu$. The difference, however, was not significant $(0.05<$ $P<0.1$ ). A similar trend occurred in the case of submaintenance feeding (Table I). Thus, sarcomere length was slightly shorter for the depleted group II than for group III $(1.53 \mu$ vs. $1.67 \mu ; 0.05<P<0.1)$ and group I $(1.53 \mu$ vs. $1.68 \mu ; 0.05<P<0.1)$. The latter two groups, however, had almost identical values.

TABle I. EFFect of MaINTENance (Zero-energy

Balance) and Submaintenance (Negattve-

ENERGY BALANCE) AND OF COMPENSATORY

GroWTH (REPLETION) ON MicrosCOPIC Aspects of Lamb $L$. dorsi Muscle

The values of a characteristic carrying same letter are not significantly different from one an other $(P>0.05)$.

\begin{tabular}{lcc}
\hline \multicolumn{1}{c}{$\begin{array}{c}\text { Nutritional status } \\
\text { of lambs }\end{array}$} & $\begin{array}{c}\text { Fibre } \\
\text { diameter } \\
(\mu)\end{array}$ & $\begin{array}{c}\text { Sarcomere } \\
\text { length } \\
(\mu)\end{array}$ \\
\hline $\begin{array}{l}\text { Expt. i } \\
\text { Maintenance group }\end{array}$ & $33.18 \pm 4.77^{\mathrm{a}}$ & $1.484 \pm 0.171^{\mathrm{b}}$ \\
$\begin{array}{l}\text { Control group } \\
\text { Expt. ii }\end{array}$ & $36.80 \pm 2.50^{\mathrm{a}}$ & $1.635 \pm 0.173^{\mathrm{b}}$ \\
$\begin{array}{l}\text { Group I (Datum) } \\
\text { (8 10 week old) }\end{array}$ & $33.29 \pm 2.66^{\mathrm{ed}}$ & $1.683 \pm 0.068^{\mathrm{a}}$ \\
$\begin{array}{l}\text { Group II (Depleted) } \\
\text { (15 week old) }\end{array}$ & $23.18 \pm 2.49$ & $1.535 \pm 0.136^{\circ}$ \\
Group III (Control) & $35.73 \pm 5.42^{\mathrm{ed}}$ & $1.670 \pm 0.050^{\circ}$ \\
(15 week old) & & \\
Group IV (Control) & $37.29 \pm 4.20^{\circ}$ & $1.706 \pm 0.052^{\circ}$ \\
(25 30 week old) & & \\
Group V (Repleted) & $37.05 \pm 1.40^{\circ}$ & $1.709 \pm 0.045^{\circ}$ \\
(25 30 week old) & & \\
\hline
\end{tabular}


3. Collagen, elastin and fat cells. In general, the fibres varied considerably in size within samples as has been reported by earlier studies. ${ }^{17,18}$ The muscle fibres of lambs of maintenance and submaintenance groups were small, some having a corrugated appearance while others were granular and occasionally broken up. This was particularly true for the samples from lambs which were kept on submaintenance feeding. Although the distribution of collagen varied within samples, it was generally dense and of a coarse fibrillar type and often occurred in thick bundles, especially in the vacinity of depleted fat cells in the case of the maintenace and submaintenance groups.

The fibres of muscle from the control groups in both experiments had a granular appearance. The collagen varied from very fine to medium dense, and both fibrillar and smooth types were visible. There was no obvious difference in the distribution or in the nature of elastin between underfed and control groups. The intra-muscular fat deposits in all samples from control groups were well distributed and the fat cells were filled. The general appearance of both the muscle fibres and the elastin of sample from pre-stressed group I was identical with that of the other high plane control groups but in the former fine to medium fibrillar type collagen occurred in a thin delicate sheet. Scattered deposits of fat cells varying from small to large size with little or no collagen were present.

The elastin was spears in all samples (including controls) though it could frequently be seen in the walls of blood vessels; only occasionally a few fine fibrillar structures were seen in association with the collagen of fat deposits. Fat was practically absent in all samples from maintenance and submaintenance groups except in two lambs from the maintenance group where fat deposits with very small fat cells were noted. In other samples, the location of earlier fat deposits was indicated by the "collapsed" (depleted) nature of the fat cells.

4. Ultra-structure of muscle. In general, low plane of nutrition was associated with a variety of change in the fine structure of $L$. dorsi muscle and the changes were more promi-

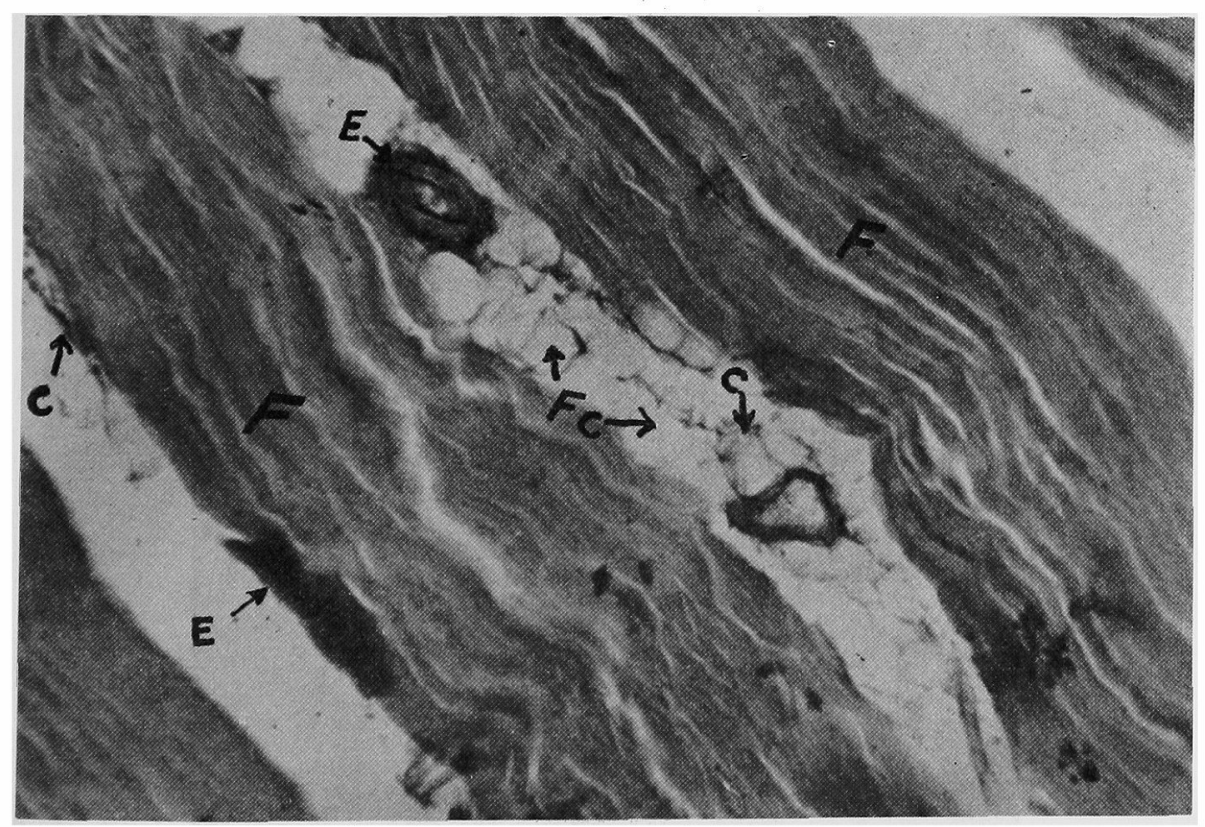

FIg. 1. Longitudinal Section of Longissimus dorsi Muscle from a Control Lamb, Showing the Distribution of Fibres ( $F$, brown), Collagen ( $C$, light violet), Elastin (E, dark violet) and Fat Cells $(\mathrm{Fc})$. 
nent in the muscle from "negative-energy balance" lambs than from "zero-energy balance" ones.

As far as the "zero-energy" groùp is concerned the electron micrographs (Figs. 2 vs. 3) indicated that the $L$. dorsi muscle had an apparent decrease in the amount and size (diameter $25 \mathrm{~nm}$ ) of glycogen granules, as compared with the controls. The fact that glycogen granules persisted in the muscle of underfed lambs, however, suggests that this substance probably has a structural-functional importance as well as (or rather than) merely an energy reserve role.

The mitochondrial matrices, even in control lambs varied in shape and size (Fig. 2). They were variously arranged in the inter myofibrillar space, usually bearing no precise relationship with the sarcomere periodicity. In some areas they accounted for a substantial protion of the fibre volume, while in others they were scanty. However, an apparent decrease in the number of mitochondria in the muscle from maintenánce lambs (Figs. 2 vs. 3) was observed.

The sarcoplasmic reticulum was sparse in all samples and appeared to be unrelated to nutritional state. The T-system on the other hand seemed comparatively conspicuous in most of the samples but it, too, seemed unrelated to the nutritional status of the lambs. There was no obvious change in the form of the actin or myosin filaments. The transverse striations of the myofibrils appeared normal.

In the case of submaintenance feeding, there was a considerable difference in the fine structure of muscle from depleted group II and control (group III) lambs (Fig. 4). The examination of micrographs suggests that although atrophy was seen in muscle of the

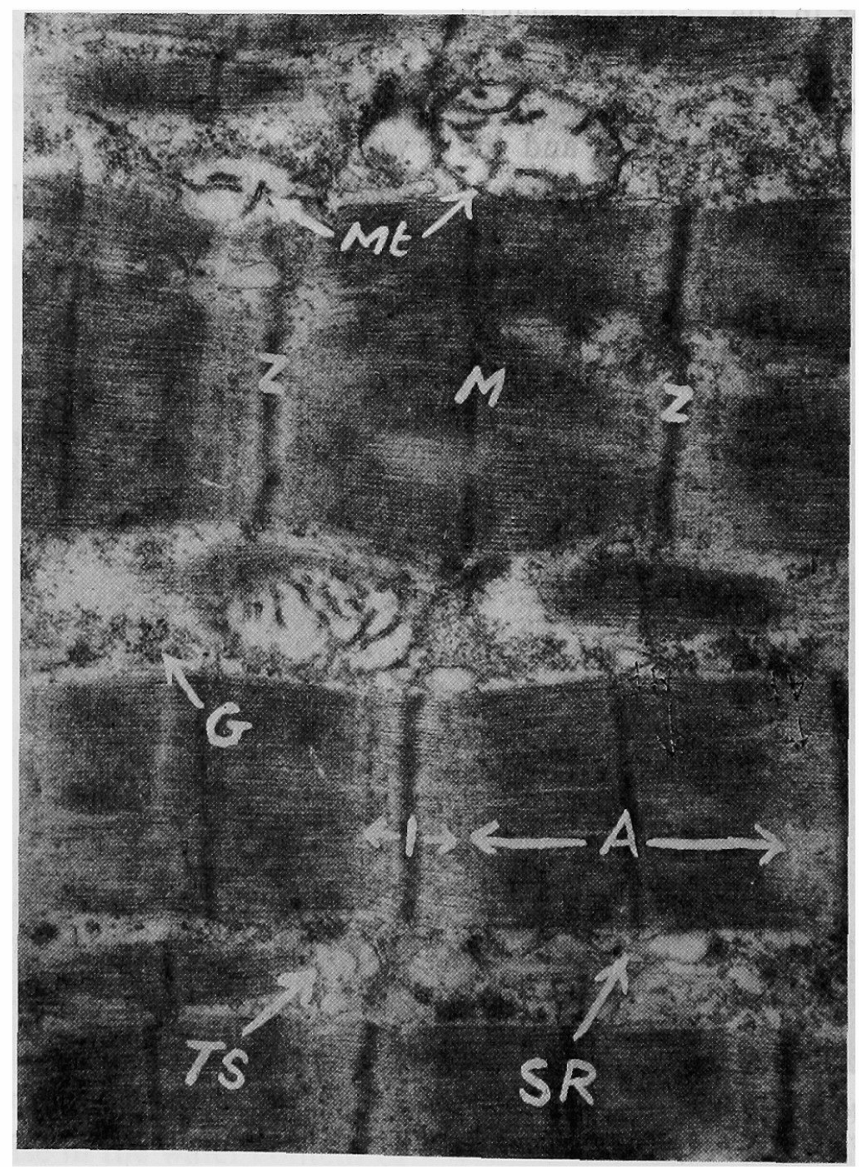




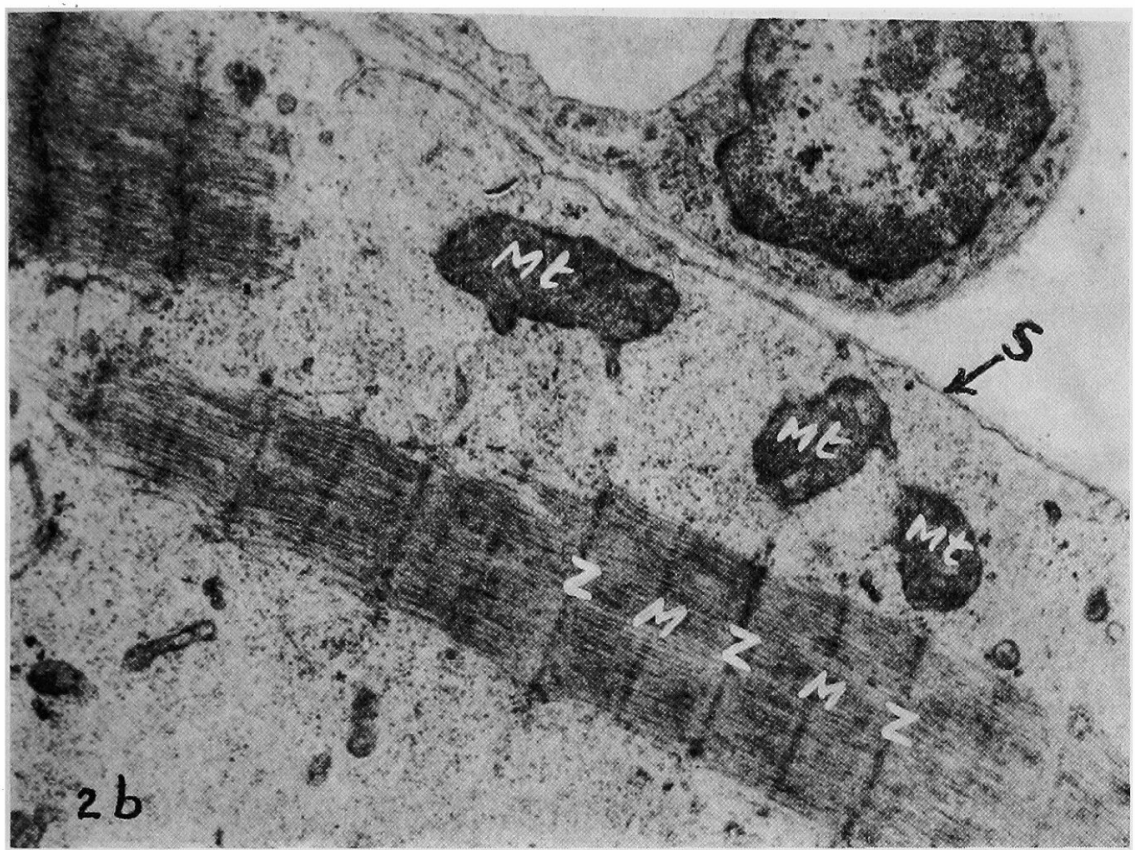

$2 \mathrm{~b}$

Fig. 2. Electron Micrographs of Longissimus dorsi Muscle from a Control Lamb (datum group I), Showing Normal Myofibrils and Cellular Components: the mitochondria (Mt), sarcoplasmic reticulum (SR), transverse system (TS), glycogen granules (G), Z-lines (Z), I-band (I) consisting of actin filaments, A-band (A) consisting of myosin filaments M-line (M) and sarcolemma (S). Figure $2 b$ shows the synthesis of new myofibril.

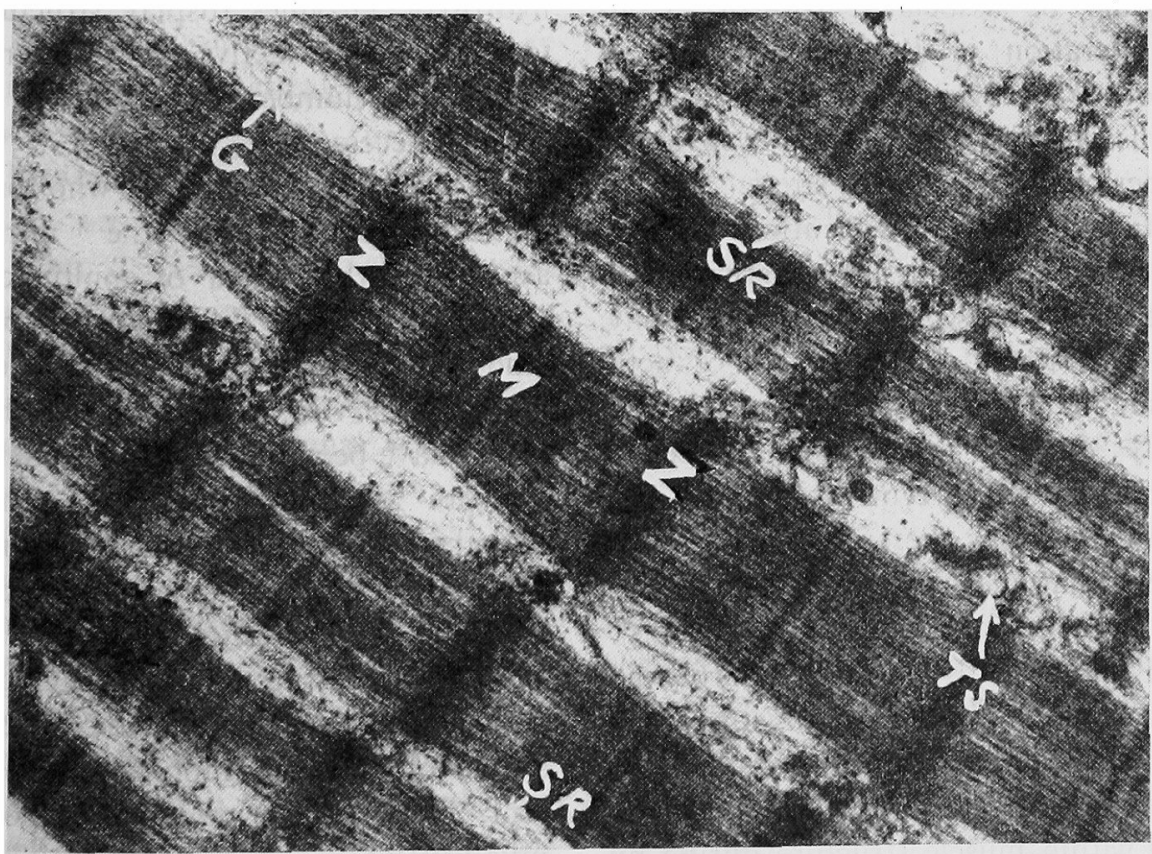

FIG. 3. Electron Micrograph of Longissimus dorsi Muscle of a Lamb from Maintenance (zeroenergy balance) Feeding Group, Showing Normal Myofibrils.

However, mitochondria are lacking and glycogen granules are scanty. For abbreviations refer to Fig. 2. 


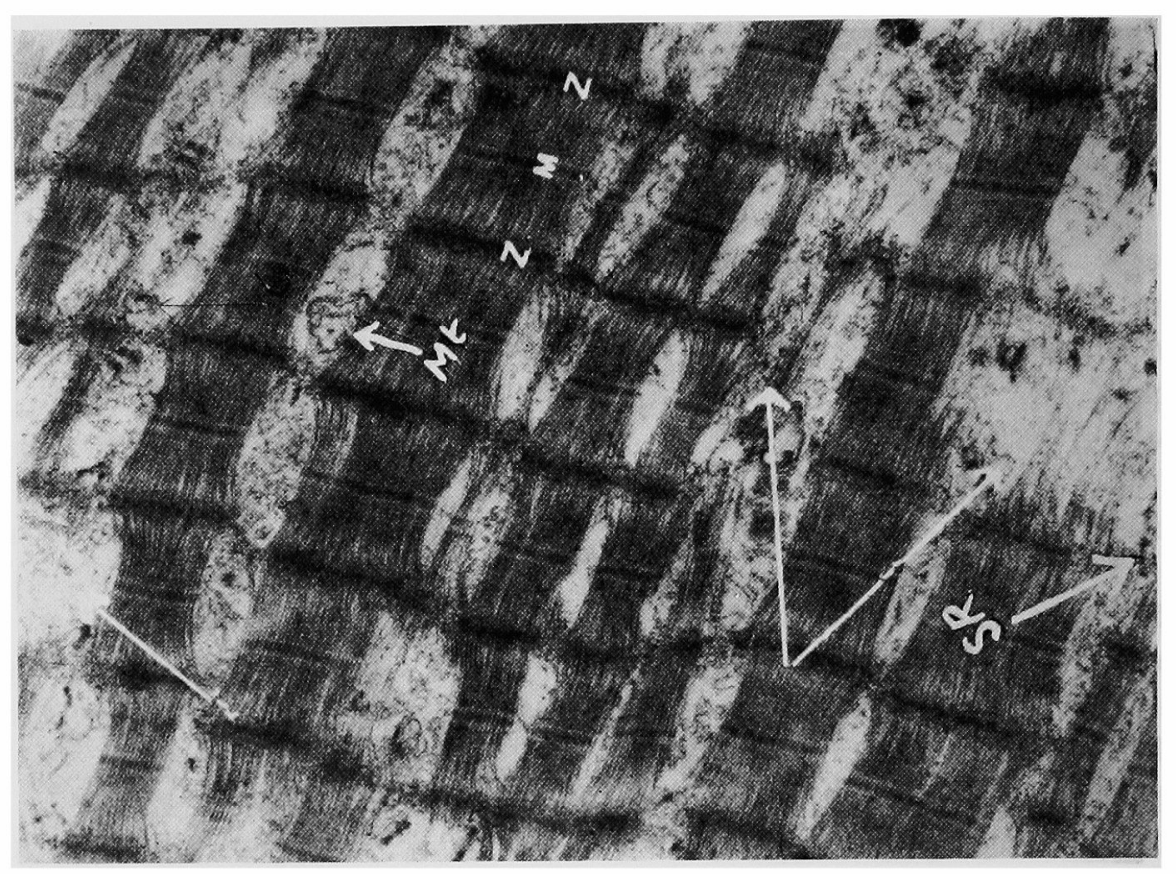

FIG. 4. Electron Micrograph of Longissimus dorsi Muscle from a Depleted Lamb, Submaintenance (negative-energy balance) Feeding Group II, Showing Frequent Breakdown of Myofibrils (arrow), Lack of Mitochondria and Scanty Glycogen Granules.

For abbreviations refer to Fig. 2.

underfed group, no consistent sub-cellular pattern could be associated with it. Conspicuous alteration in the ultrastructure of the muscle was, however, noticed; the magnitude of this varied betwen lambs even under identical periods of nutritional stress.

In addition to changes as mentioned above, there appeared to be extensive disruption in the muscle fibres with scattered foci of atrophy, including occasional disappearance of actin and myosin filaments, suggestive of myolysis presumably due to undernutrition. These observations are in agreement with the biochemical observations presented in Part II. ${ }^{12}$, The scattered nature of these foci must remain a matter for speculation; however, Fritz's ${ }^{19}$, suggestion that recently synthesized protein is preferentially catabolized during fasting could have relevance. Even then there must be some mechanism to account for the catabolism of myofibrils within muscle structure during nutritional stress. In the original biochemical concept of 'lysosomes' it was postulated that lysosomes form a single population of enzymic- ally homogeneous granules within which the hydrolytic enzymes display structure-like latency, become active only after death. ${ }^{20}$ However, a number of reservations have since become necessary. ${ }^{21}$ )

Recently, Threadgold, ${ }^{22)}$ who presented a detailed picture of the ultrastructural aspects of the origin of multinucleate cells (syncytia) and the differentiation process, extended the latest views on myogenesis and myolysis in vivo. According to him lyososomes have been identified as primary, secondary, pre- and post-lyososomes. These classes perhaps represent two distinct morphological processes in cell, namely, hetrophagy and autophagy. The latter is believed to be concerned with intracellular scavenging, as a part of continuing cell maintenance, metamorphosis, involution and mobilization of cell content. The same may be responsible for myolysis in muscle syncytia during chronic undernutrition. This may well be regarded as one of the homeostatic mechanisms for survival of the functioning cells under adverse condi- 
tions.

Despite myolysis in the muscle, there was no change in the transverse striations of the normal portions of degenerating fibres. $\mathrm{Al}$ though Pappenheimer et al. ${ }^{23}$ reported that in the case of acute dystrophy, segmental necrosis of muscle fibres occurred with a loss of cross striations and transformation of the contractile filaments into a homogeneous coagulum, such extreme changes in the living muscle would be incompatible with performance of the contraction-relaxation cycle.

Although the present study does little to explain the mechanism of breakdown of the myofibrils within the muscle during nutritional stress, at least it seems significant that the dietary regimes did appear to alter the number of mitochondria within the sarcoplasm. However, their frequency did not decrease beyond a certain limit in spite of the fact that some animals lost considerable weight on the submaintenance feeding.

\section{B. Effect of compensatry growth on muscle structure}

1. Fibre diameter and sarcomere length. The data in Table I show that muscle fibre diameter increased dramatically during the recovery period from $23.8 \mu$ to $37.05 \mu$. The difference between repleted group $\mathrm{V}$ and control group IV was not significant $(37.05 \mu \mathrm{vs}$. $37.29 \mu)$. Fibre diameter also increased with an increase in the age of optimally growing lambs. These findings confirm the previous work which has shown that the fibre diameter of the muscle returns to normal size on restoring the animal to an adequate feeding regime..$^{3,15}$ ) Table I also shows that the rehabilitated group $\mathrm{V}$ and control group IV had a similar sarcomere lergth $(1.706 \mu$ vs. $1.709 \mu \quad P<0.05)$. This indicates that the slight difference in sarcomere length associated with undernutrition vanished during the period of compensatory growth. The difference between III and IV $(1.670 \mu$ vs. $1.709 \mu)$ revealed a tendency for the sarcomere length to increase with advance in age of the normally growing lambs.
The general appearance of muscle fibres and the distribution of elastin in samples from repleted group $\mathrm{V}$ and control group IV was similar to those described above for normally growing lambs. However, the collagen was moderately dense and coarse and the fat cells small in repleted lambs. On the other hand, in control group IV, collagen, of both fibrillar and smooth types, varied from small to medium in amount, and was present in scattered form. Fat was in abundance, evenly distributed in medium to large fat cells.

2. Ultra-structural features. Figure 5 reveals restoration of the normal ultrastructural pattern during the compensatory growth period. Glycogen and mitochondria were apparently restored, both in amount and in distribution, while the myofilaments of actin and myosin were also appreciably regenerated. This is in keeping with the electron microscope studies of Fawcett ${ }^{24}$ ) and Bernhard and Rouiller $^{4}$ on liver cells which indicated a gross reduction in endoplasmic reticulum in starved rats followed by regeneration within a few hours of feeding protein. These observations also substantiate the result derived by means of biochemical studies. ${ }^{12)}$

\section{DISCUSSION}

In a comprehensive review, Munro ${ }^{25}$ states that changes caused by undernutrition appear to have different implication in different tissue of the animal body. For example, in liver cells, which are non-dividing, low protein intake results in rapid changes in the endoplasmic reticulum, whereas in non-dividing pancreatic cells, the initial change is in the amount of protein per cell; the RNA content being unaffected. On the other hand, in the intestinal mucosa, which is a rapidly dividing tissue, the nutritional stress of the animal expresses itself by changing the rate of cell division without any alteration in cell composition.

The picture of tissue lability of muscle cyncytia in relation to nutritional stress seems more complicated. In this case such intracellular components as sarcoplasmic reticulum 

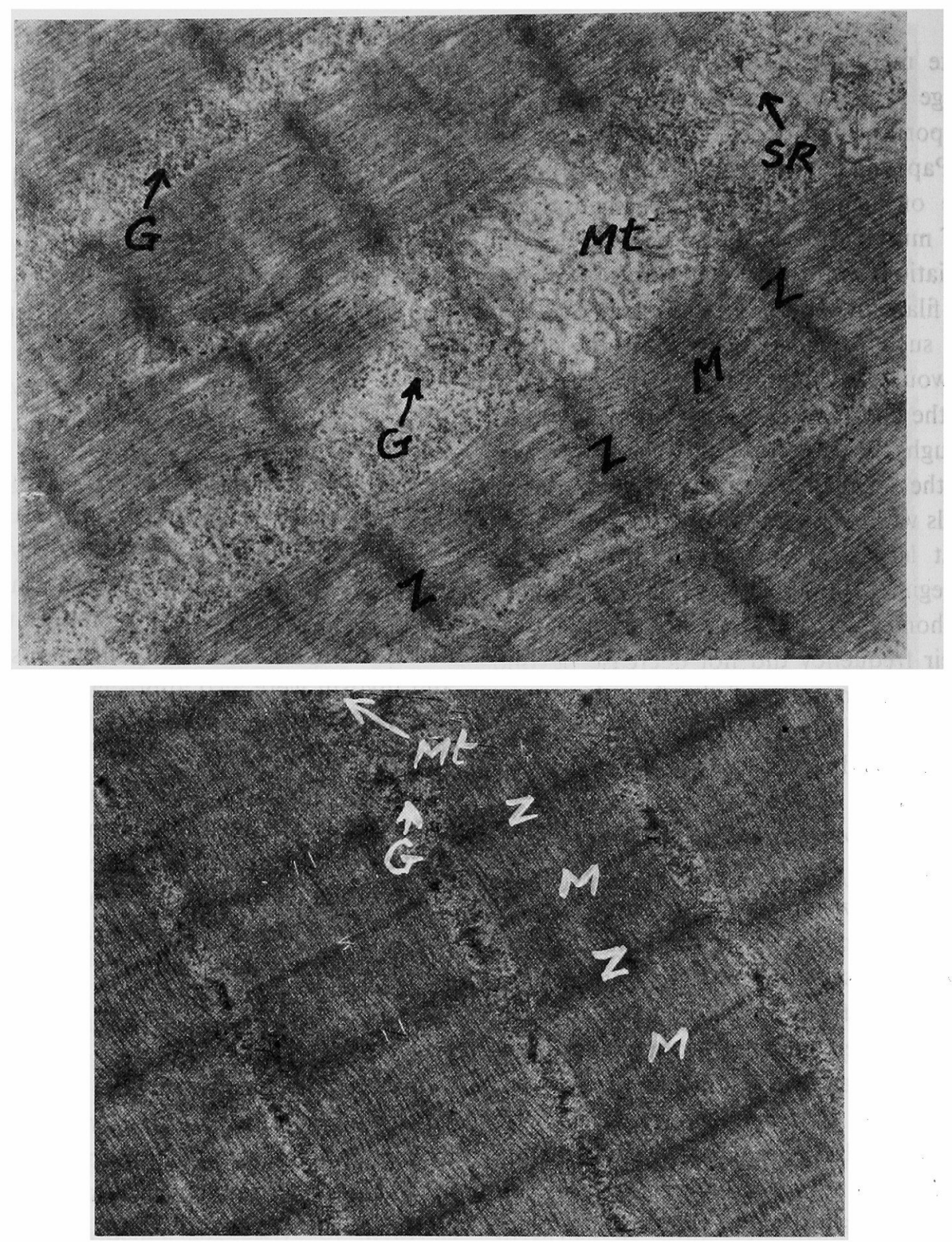

FiG. 5. Electron Micrographs of Longissimus dorsi Muscle from Repleted Lambs (group V), Showing the Regeneration of Myofibrils.

The cellular components again appear normal. For abbreviations refer to Fig. 2.

and T-system appear to be least affected by nutritional stress, while the number of mitochondria and glycogen granules significantly reduces by both maintenance and submaintenance feedings. On the other hand actin and myosin filaments are degenerated only by submaintenance feeding regime. The extra-cellular connective tissues of muscle seem apparently resistant, rather become more dense and coarse as a result of undernutrition.

The reversibility of the ultrastructural changes which occured especially in the intracellular components of animal's muscle due to underfeeding was also proved after restoring the animals to an adequate nutrition. However, the changes in extra-cellular connective tissues, which occured during underfeeding period, seem to be irreversible. 
Acknowledgements. Thanks are due to Dr. R. C. Henrickson (CSIRO, North Ryde; now Associate Professor of Anatomy at Columbia University, New York) for his cooperation in conducting the electron microscopic studies. One of the authors (A. Asghar) was a Commonwealth Interchange Scheme Fellow from Pakistan.

\section{REFERENCES}

1) K. E. Mason, in "Structure and Function of Muscle," Vol. 3, ed. by G. H. Bourne, Academic Press, New York, 1960, p. 171.

2) J. I. Quin, Fmg. S. Afr., 13, 149 (1938).

3) N.T. M. Yeates, J. Agric. Sci. Camb., 62, 267 (1964).

4) W. Bernhard and C. Rouiller, J. Biophys. Biochem. Cytol., 2, (Suppl. No. 4) 73, (1956).

5) D. Svoboda, H. Grady and J. Higginsen, Lab. Invest., 15, 731 (1966).

6) A. Asghar and N. T. M. Yeates, Agric. Biol. Chem., 43, 429 (1979).

7) H. M. Carleton and R. A. B. Drury, "Histological Techniques," Oxford University Press, London, 1957.

8) F.S. Siostrand, "Electron Microscopy of Cells and Tissues," Vol. 1, Academic Press, New York, 1967, p. 9.

9) T. E. Powell, C. W. Philott and M. D. Maser, J. Cell Biol., 23 (1964).

10) J. H. Lufts, J. Biophys. Biochem. Cytol., 9, 409 (1961).
11) E. S. Renolds, J. Cell Biol., 17, 208 (1963).

12) A. Asghar and N.T. M. Yeates, Agric. Biol. Chem., 43, 437 (1979).

13) S. Frenk, J. Metcoff, F. Gomez, R. RamosGalyan, J. Cravioto and I. Antonowicz, Pediatric, Springfield, 20, 105 (1957).

14) J. W. T. Dickerson and R. C. McCance, Br. J. Nutr., 14, 331 (1960).

15) J. L. Raath, M. Sc. Thesis, University of Pretoria (1941).

16) G. K. Hight and R. A. Barton, New Zealand J. Agric. Res., 8, 602 (1965).

17) V.S. V. Fernand, Ph. D. Thesis, University of London (1949).

18) H. J. Tuma, J. H. Venable, P. R. Wuthier and R. L. Henrickson, J. Anim. Sci., 21, 33 (1962).

19) I. Fritz, Endocrinology, 58, 493 (1956).

20) C. deDuve, in "Methods of Separation of Subcellular Structurel Components," ed. by J. K. Grant, Biochem. Soc. Symp., 23, 103 (1963).

21) G. J. Levvy and J. Conchie, Prog. Biochem. Molec. Biol., 14, 105 (1964).

22) L. T. Threadgold, "The Ultrastructure of the Animal Cell," 2nd ed. Pergamon Press, Oxford, 1976.

23) A. M. Pappenheimer, M. Goettsch and E. Jungherr, Bull. Storrs Agri. Expt. Sts., No. 299 (1939).

24) D. W. Fawcett, J. Natl. Cancer Inst, 15 (Supp.), 1475 (1955).

25) H. N. Munro, in "Mammalian Protein Metabolism," ed. by H. N. Munro and J. B. Allison, Vol. 1, Academic Press, New York, 1964, p. 381. 